\title{
Conceitos matemáticos e tecnologias digitais: um olhar para o reflorestamento
}

\section{Mathematical concepts and digital technologies: a look at reforestation}

\author{
Michele Silva da Mata Caetano \\ Instituto Federal de Educação, Ciência e Tecnologia do Espírito Santo \\ michelemata.hl@gmail.com
}

Ana Paula Azevedo Moura

Instituto Federal de Educação, Ciência e Tecnologia do Espírito Santo anapaula.amoura@gmail.com

Jorge Schneider

Instituto Federal de Educação, Ciência e Tecnologia do Espírito Santo jorgeschneider21@gmail.com

\section{Ronaldo Leffler}

Instituto Federal de Educação, Ciência e Tecnologia do Espírito Santo ronaldoleffler@hotmail.com

\section{Marize Lyra Silva Passos}

Instituto Federal de Educação, Ciência e Tecnologia do Espírito Santo marize@ifes.edu.br

\section{Rsumo}

Esse trabalho é fruto de uma pesquisa de alunos do Mestrado Profissional em Educação em Ciências e Matemática ofertado pelo Instituto Federal do Espírito Santo (Ifes), referente à disciplina de Tecnologias Educacionais I, onde foram proporcionados espaços de debates e reflexões sobre a aplicação de recursos tecnológicos computacionais na Educação em Ciências e Matemática, tanto como fundamentação à aprendizagem quanto à discussão sobre possíveis estratégias didático-pedagógicas. Foram desenvolvidas estratégias metodológicas por meio de um projeto pedagógico interdisciplinar a filhos de agricultores familiares, onde se utilizou tecnologias digitais (TD) visando facilitar o cálculo de áreas geográficas, bem como discutir aspectos relacionados à preservação e à recuperação de áreas ambientais. Para isso foram feitas 


\section{aEducitec \\ ISSN: $2446-774 X$}

discussões aprofundamentos sobre recursos hídricos e código florestal, bem como aulas de campo com coleta de dados utilizando as TD e constatações in loco. Assim, no decorrer do trabalho foram discutidos diversos conteúdos, mesclando conceitos da matemática, da topografia e relacionando-os ao meio ambiente, por meio da temática do reflorestamento. Para a execução das atividades utilizamos três softwares, que permitiram uma abordagem diferenciada dos conteúdos, proporcionando aos alunos refletirem a respeito do meio onde estão inseridos e a importância do equilíbrio entre produção e preservação do meio ambiente.

Palavras-chave: Informática. Educação ambiental. Educação Matemática.

\section{Abstract}

This work is the result of a research of students of the Professional Master's Degree in Science and Mathematics Education offered by the Federal Institute of the Holy Spirit (Ifes), referring to the discipline of Educational Technologies I, where spaces of debates and reflections on the application of resources were provided computational technologies in Science and Mathematics Education, as well as a foundation for learning and discussion about possible didacticpedagogical strategies. Methodological strategies were developed through an interdisciplinary pedagogical project for children of family farmers, using digital technologies (DT) to facilitate the calculation of geographical areas, as well as discuss aspects related to the preservation and recovery of environmental areas. For this, discussions were conducted on water resources and forest code, as well as field lessons with data collection using the TD and in loco findings. Thus, during the course of the work, several contents were discussed, merging concepts of mathematics, topography and relating them to the environment, through the theme of reforestation. For the execution of the activities we used three softwares, which allowed a differentiated approach of the contents, allowing the students to reflect on the environment where they are inserted and the importance of the balance between production and preservation of the environment.

Keywords: Computer science. Environmental education. Mathematical Education.

\section{Introdução}

O presente trabalho relata um trabalho interdisciplinar no qual alunos do ensino médio de uma Escola Estadual, localizada no município de Santa Maria de Jetibá no Espírito Santo (ES), por meio do uso de tecnologias digitais e de conceitos matemáticos, puderam analisar, refletir e estabelecer áreas geográficas em que consideraram necessário um reflorestamento. A escola apresenta um alto índice de evasão, considerando a passagem de nível do fundamental II para o nível médio, visto que grande parte dos alunos passa a integrar a mão de obra familiar no cultivo das propriedades rurais e, devido a isso, o número de alunos é reduzido significativamente em relação aos padrões encontrados na rede 


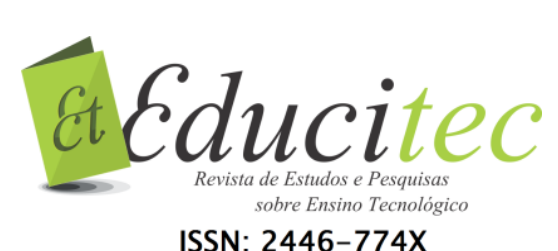

estadual de ensino.

Assim, visando atender algumas peculiaridades encontradas com relação a esta questão, a escola adota uma oferta diferenciada de disciplinas voltadas para realidade agrícola, bem como a Pedagogia da Alternância que, em parte, ajuda a atenuar a evasão, segundo Nosella:

\begin{abstract}
Resumidamente, podemos dizer que a denominação 'pedagogia da alternância' se refere a uma forma de organizar o processo de ensinoaprendizagem alternando dois espaços diferenciados: a propriedade familiar e a escola. Liga-se, pois, tanto pela sua origem como pelo seu desenvolvimento, à educação no meio rural.(NOSELIA, 2012, p. 29)
\end{abstract}

Tendo em vista que mais de $90 \%$ dos alunos são filhos de agricultores, o trabalho com o uso de tecnologias no desenvolvimento interdisciplinar entre matemática, topografia e meio ambiente, se deve a necessidade da conscientização dos filhos de agricultores com relação à preservação do meio ambiente, visando manter a proteção dos recursos hídricos. Assim, a proposta buscou usar do espaço escolar para propiciar momentos de reflexão em relação ao desmatamento, para que este não seja predatório e desenfreado, acarretando e agravando problemas sérios no ecossistema e, consequentemente, na sociedade, como: erosão, assoreamento dos rios, diminuição e até desaparecimento de espécies da fauna e da flora local, escassez hídrica, dentre outros. Nesse sentido, tenta-se responder a seguinte questão: como a tecnologia pode favorecer o processo de ensino e aprendizagem na identificação das áreas geográficas no entorno da escola que necessitam de uma maior atenção quanto ao seu desmatamento e auxiliar no cálculo dessas áreas para um futuro reflorestamento?

Para responder a questão, definiu-se alguns objetivos específicos, a saber: identificar aplicativos que apoiam o cálculo das áreas, considerando o contexto em que os alunos estavam inseridos; conhecer os softwares e os aplicativos (app) selecionados e suas potencialidades; discutir os conceitos matemáticos ângulos, escalas, distâncias inacessíveis, dentre outras; analisar e calcular a(s) área(s) que necessita $(\mathrm{m})$ de reflorestamento, por meio de tecnologias digitais, e verificar se as tecnologias utilizadas facilitaram o processo e a reflexão quanto a utilização destas para além do âmbito escolar.

Para tal, foram desenvolvidas atividades relacionadas às disciplinas de matemática e topografia, sendo abordados conteúdos como levantamento planimétrico, vante e escala na disciplina de Topografia e trigonometria, área de figuras planas, perímetro e geometria analítica na disciplina de Matemática, além do tema transversal, Meio Ambiente.

\title{
Educação Ambiental e Agricultura
}

Sabemos que a escola oportuniza espaço para a abordagem e discussão de temas relevantes para a sociedade. Sendo assim, é espaço para abordagem de problemáticas do cotidiano dos alunos e suas famílias. Um tema importante, nesse sentido, é a educação ambiental. Quando o assunto meio ambiente e tratado em uma escola de interior, de contexto rural, sem dúvida necessita-se dar um enfoque diferenciado ao tema devido às problemáticas mais comuns serem diferentes das que são encontradas no meio urbano, embora saibamos 


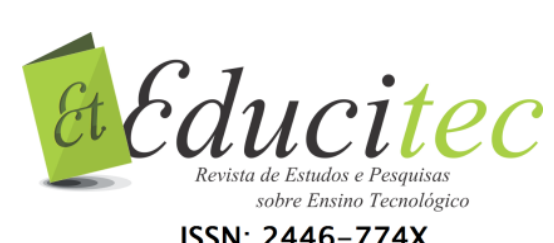

que toda e qualquer discussão nesse sentido sempre é válida e conhecer as diferentes problemáticas também é extremamente importante.

Nesse sentido, é importante levar em consideração o Código Florestal, pois ele regulamenta como devem ser feitas ações que envolvem supressão de vegetação nativa necessárias às atividades do setor agrícola. Notamos assim, que há necessidade de equilíbrio entre o setor da produção agrícola e o meio ambiente, pois atividades produtivas predatórias levam a graves danos ao meio ambiente e consequentemente a sociedade. Nesse sentido, um dos pontos mais importantes a ser abordados em uma proposta pedagógica, voltada para filhos de agricultores, são as ditas Áreas de Preservação Permanente (APP) e as de Reservas Legais $(R L)$.

A APP é uma área protegida, coberta ou não por vegetação nativa, com a função ambiental de preservar os recursos hídricos, a paisagem, a estabilidade geológica e a biodiversidade, facilitar o fluxo gênico de fauna e flora, proteger o solo e assegurar o bem-estar das populações humanas. Exemplos de APP são: matas ciliares, nascentes, topos de morros, encostas e manguezais. As reservas legais são áreas localizadas dentro de uma propriedade ou posse rural com a função de proteger a vegetação e assegurar o uso econômico de modo sustentável dos recursos naturais do imóvel, auxiliando a conservação e a reabilitação dos processos ecológicos e promovendo a conservação da biodiversidade, bem como o abrigo e a proteção de fauna silvestre e da flora nativa. (MACHADO; ANDERSON, 2016, p. 18)

Nota-se que se trata de áreas dentro das propriedades rurais que devem ser preservadas. O ideal seria que essas áreas não precisassem de reflorestamento, mas sabemos que a realidade muitas vezes é outra. Por serem estratégicas, precisam ser parte de problemáticas discutidas no ambiente escolar, quando possível por mais disciplinas pois "[...] a questão ambiental não é compreensível apenas a partir das contribuições da Geografia. Necessita de conhecimentos históricos, das Ciências Naturais, da Sociologia, da Demografia, da Economia, entre outros" (BRASIL, 1998, p. 27). Assim, trata-se de uma temática que perpassa várias áreas de conhecimento.

\section{Tecnologias Digitais na Matemática}

Vivemos em uma sociedade que passa por inúmeras transformações e que está em constante desenvolvimento. As últimas décadas trouxeram uma grande evolução para a humanidade, que foi possível graças ao uso das tecnologias. Corroboramos com os autores, quando estes afirmam que:

O uso de videocassetes, aparelhos de CD e DVD, computadores, notebooks, celulares, TV a cabo e mais um mundo de aparelhos e tecnologias mudou e continua mudando a forma como nos comunicamos e a maneira como vivemos. (FÁVERO; NUNES, 2011, p. 174)

Entretanto, o quadro e o giz, os livros com os mesmos exemplos, a lista de exercício exaustiva, a régua, ainda, continuam sendo os protagonistas dentre os recursos utilizados em sala de aula. "O ensino da matemática carrega consigo traços de uma prática mecânica da sua forma de ser ensinada e os objetivos são 


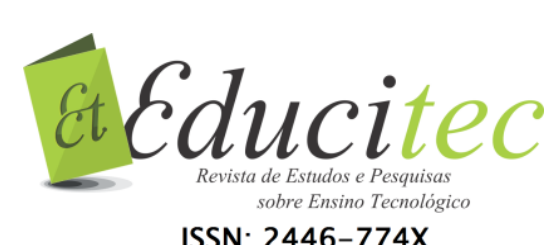

ISSN: $2446-774 X$

reformulados para que ocorram mudanças principalmente nos seus resultados" (VASCONCELOS et al, 2015, p. 03). Em contrapartida, a presença de aparelhos celulares em sala de aula, em seus mais desenvolvidos modelos, é inevitável, conforme relata a Organização das Nações Unidas para a Educação, a Ciência e a Cultura (UNESCO) em suas Diretrizes de Políticas para Aprendizagem Móvel (2014, p. 12):

Hoje, as tecnologias móveis são comuns, mesmo em áreas onde escolas, livros e computadores são escassos. À medida que o preço dos telefones celulares vai diminuindo, provavelmente, cada vez mais pessoas, adquirem aparelhos móveis e aprendem a usá-los, inclusive aquelas que vivem em áreas mais vulneráveis.

Desta forma, a tecnologia tem ganhado espaço cada vez maior no cotidiano dos mais variados espaços, sendo de ensino ou não. Esta crescente presença do celular e do computador em diversas atividades em nossas vidas, assim como no contexto escolar, nos leva a refletir sobre as possibilidades de utilização de sua utilização no processo de ensino e aprendizagem, no desenvolvimento da prática educativa, considerando suas potencialidades e limitações no contexto escolar que estamos inseridos.

Nessa sociedade do conhecimento e da aprendizagem, professores, alunos e a própria escola assumem novos papéis. É nesse contexto que pensamos na atuação do profissional/professor, que atue direta ou indiretamente com a informática na Educação (CALDAS; et al, 2011, p.16).

Entretanto, mesmo que os educadores tenham o interesse de utilizar tecnologia em suas aulas, não se pode desconsiderar as dificuldades/limitações encontradas quanto à sua utilização na prática pedagógica, em que uma delas é a falta de disponibilidade de um laboratório de informática nas escolas. Mas, ainda que a escola não conte com um laboratório de informática equipado, percebemos que outras tecnologias podem entrar em sala de aula com o intuito de auxiliar/facilitar a compreensão de diferentes conceitos, a execução de tarefas, por exemplo, o celular, pois os alunos podem utilizar os aplicativos em telefones celulares e tablets, a fim de estudar na escola e em suas casas diversas disciplinas. Nessa perspectiva, ao conceituar tecnologia, deve-se pensar em um contexto mais amplo, em que o laboratório de informática é apenas um entre as inúmeras tecnologias disponíveis e presentes no cotidiano da comunidade escolar.

O conceito de tecnologia educacional pode ser enunciado como o conjunto de procedimentos (técnicas) que visam "facilitar" os processos de ensino e aprendizagem com a utilização de meios (instrumentais, simbólicos ou organizadores) e suas conseqüentes transformações culturais. (REIS, 2009, p. 4-5)

As metodologias como a modelagem matemática, a resolução de problemas, a história da matemática e uso de jogos, dentre outras, podem ser abordadas por meio da utilização de diversas tecnologias, um vídeo do YouTube, um aplicativo de celular, um software, por exemplo, recursos que podem ser utilizados para fins educacionais e que essa utilização não vai depender da disponibilidade de computadores. Para Moran (2013) os estudantes estão prontos para utilizar a tecnologia, porém os professores ainda estão despreparados, pelo fato de não 


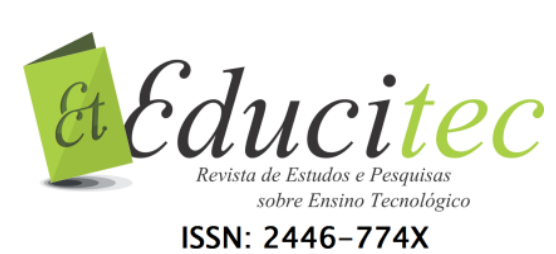

estarem familiarizados com as ferramentas que a tecnologia oferece. Muitos professores ainda não fazem mudanças na metodológicas em suas aulas, continuam com aulas repetitivas e de forma controladora, sem dinamismo e sem a utilização de recursos tecnológicos digitais

Devido a este quadro, o professor Ubiratan D'Ambrosio ressalta a importância das tecnologias e as relações com a Matemática; e faz comentário a respeito do assunto em seu blog - é impossível evitar a diversidade de cultura, como:

\begin{abstract}
Ao longo da evolução da humanidade, Matemática e tecnologia se desenvolveram em íntima associação, numa relação que poderíamos dizer simbiótica. A tecnologia entendida como convergência do saber (ciência) e do fazer (técnica), e a matemática são intrínsecas à busca solidária do sobreviver e de transcender. A geração do conhecimento matemático não pode, portanto ser dissociada da tecnologia disponível (D`AMBROSIO, 2011, s.n.p).
\end{abstract}

Essa relação se dá conforme o contexto social e o momento histórico. Assim, nós como educadores, precisamos estar atentos à condição tecnológica do ambiente escolar no qual estamos inseridos, analisar a forma como a comunidade escolar se relaciona com as tecnologias de informação e comunicação naquele ambiente, no intuito de viabilizar propostas de ensino e aprendizagem embasadas nestes.

$\mathrm{Na}$ disciplina de matemática esse quadro configura-se como uma necessidade, pois em muitas delas não se traz discussões da vivência dos alunos para dialogar com o conteúdo, e é neste ponto que as tecnologias digitais entram como fator relevante, por servirem de ponte para o diálogo entre conhecimento científico e prático. Conforme Borba e Penteado (2007, p. 17), "[...] nesse sentido, a informática na escola passa a ser parte da resposta a questões ligadas à cidadania". De fato, é neste momento que se possibilita formar um aluno que pode usar a matemática de forma crítica para intervir em problemas do seu contexto, percebendo o papel importante das tecnologias para construção do seu conhecimento.

\title{
Aplicativos para Identificação e Cálculo de Áreas
}

O desenvolvimento da pesquisa envolveu uso de tecnologias digitais com o intuito de dinamizar a execução e, também, auxiliar na aprendizagem de alguns conceitos da matemática por meio da abordagem do tema gerador, o meio ambiente. Foram utilizados aplicativos móveis - app (application program) (Figura 1), previamente selecionados, que executam de modo offline.

- Geo Area Maps - O aplicativo (Imagem 1) é uma ferramenta para mapear distâncias e calcular áreas no mapa com grande precisão, utilizando o GPS offline. Ele possui o modo marcador inteligente onde você posiciona os pinos, delimitando a área ou distância que deseja obter.

- Topografia APP - É um aplicativo (Imagem 2) desenvolvido para o georreferenciamento e levantamentos topográficos de terrenos, projetos de redes elétricas, avenidas, ruas, loteamentos e estudos em gerais. Ele permite que o usuário exporte os dados levantados para o Autocad, Google Earth e MS Excel de forma prática. 


\section{Educitec \\ ISSN: 2446-774X}

- Google Earth - Um dispositivo (Imagem 3) que permite visualizar imagens de satélite, mapas, construções 3D e até mesmo galáxias e o fundo do mar. Além disso, possui alguns recursos mais avançados como, por exemplo, medir a área de um polígono ou a altura de um edifício, criar vídeos, importar imagens com resolução mais alta que o próprio mapa, fazer a geolocalização automática de imagens que você inserir no mapa, importar dados de outros aplicativos compatibilizados, dentre outras.

Figura 1 - Imagens dos três aplicativos

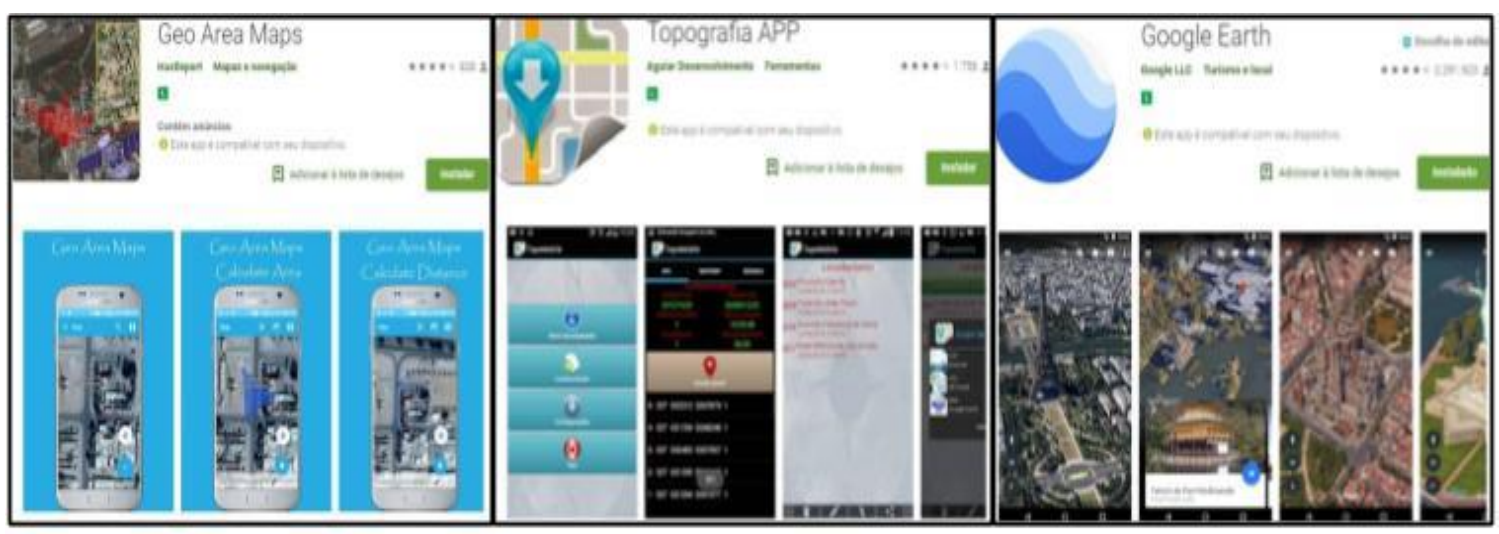

Fonte: Próprios autores (2018).

\section{Procedimentos Metodológicos}

A temática foi iniciada com a leitura e a reflexão de um artigo escrito por Fernanda Couzemenco, publicado no dia 23 de março de 2018 no jornal Século Diário intitulado de "Mobilização contra cobrança por uso da água se expande na região serrana", com duração de 1 hora/aula considerando leitura e debate. O artigo serviu de motivação para os trabalhos posteriores, visto que é uma discussão que está presente no cotidiano das famílias dos alunos. Os principais pontos levantados na discussão foram anotados, pelo professor pesquisador, em diário de bordo para posteriores análises.

Em seguida, foi proposto aos alunos irem a campo no intuito de identificar áreas necessárias e viáveis para reflorestamento. Neste momento, foram utilizados softwares selecionados anteriormente. Primeiramente, utilizamos o software Geo Area Map, de uso offline, a fim de marcar nele as áreas que os alunos acreditam ser possíveis de reflorestar para uma posterior discussão. Antes que ocorresse o cálculo das áreas pelo aplicativo, estimamos, junto aos alunos, qual o tamanho dessas áreas. Após isso, calculamos a área utilizando o aplicativo. Após discutir quais das áreas indicadas necessitam de reflorestamento, coletamos os pontos de uma delas por meio do software Topografia APP; objetivando calcular a área e, posterior a isso, a quantidade de mudas de espécies nativas que seriam necessárias para o plantio da área analisada. Estes dois momentos tiveram duração de duas horas/aulas com registros de fotos e anotações no diário de bordo.

No quarto momento, que foi de uma hora/aula, os pontos determinados pelos alunos no software Topografia APP foram transferidos para o Google Earth, 


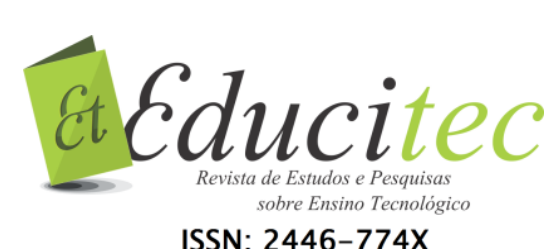

construindo o polígono determinado pelos pontos levantados e o cálculo da área do mesmo. Tendo esse valor numérico da área do polígono a ser reflorestado, os alunos estimaram a quantidade necessária de mudas de espécies nativas para cobrir todo 0 espaço e posteriormente realizaram 0 cálculo matematicamente, chegando a um valor exato. Nessa etapa utilizamos a observação e o registro em diário de bordo para avaliar o desempenho e o envolvimento dos alunos na realização das atividades.

Para finalizar, utilizamos uma hora/aula para propor uma reflexão quanto ao número de mudas nativas encontradas, a viabilidade de conseguir essas mudas junto a Secretaria Municipal de Meio Ambiente do município onde a escola está inserida. Embasados nesse diálogo reflexivo que foi realizado em grupo, solicitamos que os alunos relatassem, de modo escrito, a experiência ocorrida nessas quatro aulas.

\section{O caminhar com os alunos}

Ao buscarmos motivação com o artigo citado, percebemos que os alunos estavam inteirados do assunto tratado pela autora e envolvidos nessa mobilização contra a cobrança por uso de água, visto que de imediato eles relataram que essa é uma preocupação que eles têm desde o ano de 2017, "inclusive assinamos aquele abaixo assinado contra a cobrança de água" (aluno, Diário de Bordo, 2018). Em um diálogo com os alunos, estes foram instigados a falarem suas opiniões sobre os motivos existentes para que a água seja cobrada, e algumas questões foram relatadas pelos alunos, dentre elas o fator de desperdício da água seja devido ao fato dos sistemas de irrigação não serem adequados ao setor produtivo e também pelo seu uso indiscriminado; além do fato de muitas famílias não realizarem práticas de conservação de solo e não fazerem o reflorestamento em áreas que não são mais utilizadas para o cultivo, acarretando em erosão e assoreamento dos rios.

Após concluirmos as reflexões sobre a temática e vermos os alunos motivados para tal, foi solicitado que eles trouxessem seus smartphones na aula seguinte e, se possível, já com os aplicativos, que foram previamente apresentados, instalados visto que estes seriam usados na aula de campo. Como a atividade de campo ocorreu apenas na semana seguinte, pelo fato da alternância, foi também publicado um lembrete dias antes no grupo, no Facebook de Matemática e Física da escola, do qual os alunos fazem parte. Isso reforça o que defendem Fávero e Nunes (2011), que as tecnologias mudam a maneira de nos comunicar e viver.

Para a aula de campo, foi verificado que todos os alunos estavam com os seus smartphones e assim seguimos pela parte mais baixa da propriedade, perto do rio que corta a propriedade objetivando que os alunos encontrassem áreas que poderiam demandar necessidade de reflorestamento. Os alunos dizeram que a área perto do rio deveria ser reflorestada. E questionamo-os: "Mas por que reflorestar essa área?" Uma aluna respondeu que "por lei essa área tem que ter vegetação nativa e tem que ser reflorestada" (aluna, Diário de Bordo, 2018). A aluna fazia referência ao que está previsto na Lei $n^{0} 12.651$ de 25 de maio de 


\section{Eteducitec \\ ISSN: $2446-774 X$}

2012, no artigo 40, que versa sobre áreas de preservação permanente. Logo solicitamos que fizessem uma estimativa dessa área que eles identificaram necessitar de reflorestamento. Assim, fizeram as estimativas e um aluno falou que "estimou uns 3 hectares". Outros, logo se manifestaram contrários a essa estimativa, argumentando que "isso não dá tanto assim, 3 hectares é muito", em sequência vieram estimativas mais baixas que foram 0,5 hectare, $3 / 4$ de hectare e 1 hectare (a unidade de medida utilizada pelos alunos é hectare por estar presente em seu cotidiano como agricultores familiares).

Em continuidade, solicitamos que os alunos abrissem o aplicativo Geo Area Maps para realizar o cálculo aproximado da área que havia sido identificada, cada um no seu aparelho, com seu próprio olhar, considerando a área que cada um julgava necessário ser reflorestada, de acordo com o mapa gerado no aplicativo, conforme aparece na Figura 2.

Figura 2 - Cálculo aproximado da área identificada por um aluno

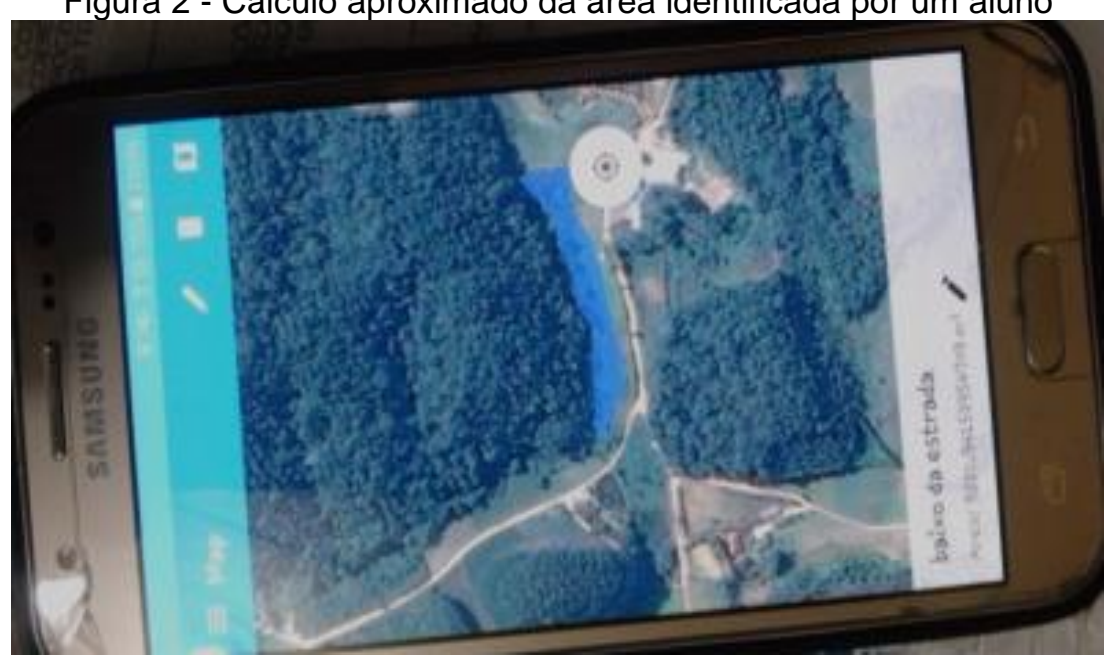

Fonte: Próprios autores (2018).

De acordo com Borba e Penteado (2007, p. 45):

Assim, o enfoque experimental explora ao máximo as possibilidades de rápido feedback das mídias informáticas e a facilidade de geração de inúmeros gráficos e expressões algébricas. Por outro lado, essa prática pedagógica estimula a utilização de problemas abertos, de formulação de conjecturas em que a sistematização só se dá como coroamento de um processo de investigação por parte dos estudantes (e, muitas vezes, do próprio professor).

Em seguida foi solicitado que dissessem as áreas obtidas pelo aplicativo. $\mathrm{Na}$ ordem que falaram foram: $5.700 \mathrm{~m}^{2}, 8.226 \mathrm{~m}^{2}, 7.955 \mathrm{~m}^{2}, 10.815 \mathrm{~m}^{2}, 8.209 \mathrm{~m}^{2}$, e $7.400 \mathrm{~m}^{2}$. Percebemos aí o olhar particular de cada um sobre a mesma área, mostrando uma análise singular do tamanho da área que consideram ter que ser reflorestada, bem com a rapidez na obtenção da informação através do smartphone, assim como defendem as Diretrizes de Políticas para Aprendizagem Móvel (UNESCO, 2014).

Em outro momento, percorremos o restante da propriedade a fim de verificar se outras áreas seriam identificadas para reflorestamento. Com uns 9 a 10 minutos de caminhada, os alunos identificaram outra área, que de acordo com o Novo 
ISSN: $2446-774 X$

Código Florestal (BRASIL, 2012) são áreas com ângulo de inclinação média maior que $25^{\circ}$ que são consideradas de preservação permanente. Passou-se então para 0 momento onde os alunos estipularam os limites para 0 reflorestamento da área. Após alguns palpites, chegaram a um acordo, delimitando a área até onde apresentava um relevo mais inclinado. Feito isso, novamente foi solicitado que estimassem o tamanho da área. Os palpites variaram de 0,5 hectare a 1,25 hectares.

Utilizando o aplicativo Topografia App, a fim de coletar pontos para determinar a poligonal da área identificada, os alunos foram andando no contorno da área com seus smartphones e, a medida que a caminhavam, iam determinando os pontos a serem coletados na área para obtenção da poligonal. Não foi apresentado nenhuma dificuldade na execução da tarefa e utilização do aplicativo. Alguns alunos disseram que "a próxima linha vai daqui até o ponto lá em cima" (aluno, Diário de bordo, 2018), o que mostrou que os alunos faziam referência ao conceito matemático de segmento de reta. Assim que os pontos terminaram de ser coletados iniciou-se a etapa da construção da poligonal, que ocorreu na aula seguinte, com uso de outro software.

Para a construção da poligonal foi utilizado o software Google Earth Pro e como este recurso não estava instalado nos computadores do laboratório de informática da escola, foi solicitado que os alunos que tivessem um notebook, os trouxessem para aula. Nesse sentido, foram utilizados três notebooks nesta etapa, e os alunos sentaram-se em duplas e trios para realizar a tarefa, que consistia em abrir o arquivo htm/ gerado pelo Topografia App, no Google Earth Pro. $\mathrm{O}$ arquivo foi disponibilizado no grupo do WhatsApp organizado pela turma. Com o arquivo em mãos iniciou-se o procedimento de construção da poligonal no software da Google, conforme mostra a Figura 3.

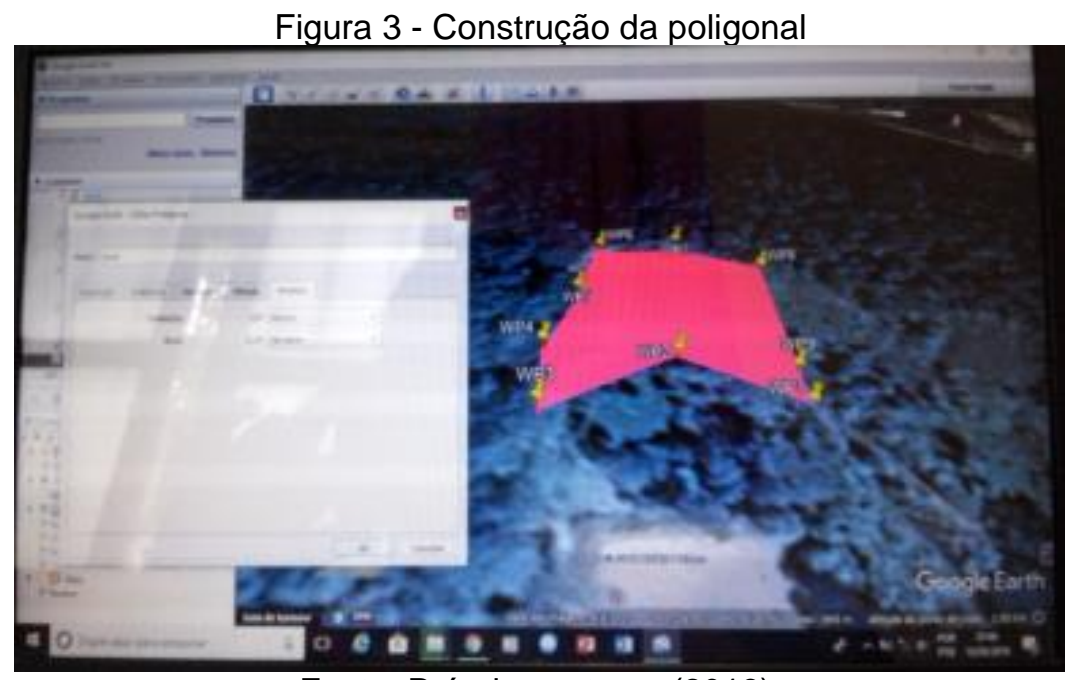

Fonte: Próprios autores (2018).

Os alunos não apresentaram dificuldade nesta tarefa e com pouco tempo já tinham os resultados em mãos. Isso reforça o que defendem Caldas et al (2011), que com as tecnologias digitais o professor e aluno assumem novos papéis no processo de ensino. Como foram feitos três levantamentos desta mesma área, cada um dos três grupos ficou responsável em calcular uma das áreas. As áreas 


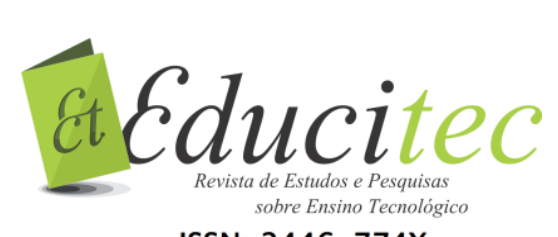

ISSN: $2446-774 X$

obtidas foram $2.681 \mathrm{~m}^{2}, 2.581 \mathrm{~m}^{2}$ e $2.427 \mathrm{~m}^{2}$.

Em seguida foram questionados sobre as figuras geométricas formadas e suas respectivas características. Responderam que eram figuras que tinham vários lados, entretanto não eram figuras regulares. Foi colocado que existiam vários ângulos que eles, a princípio, não conheciam os valores. Perguntamos também como entendiam essa área e sobre como fariam esse cálculo sem o uso do software? Um aluno respondeu que "a área não leva em conta o desnível do terreno" (aluno, Diário de Bordo, 2018). Uma outra aluna concordou e disse que "possivelmente a área real a ser reflorestada era maior" (aluna, Diário de Bordo, 2018). Faziam assim referência ao cálculo planimétrico feito pelo software e contrapondo a área real, remetendo ao conceito estudado em topografia; e com isso percebemos que o aluno, na realidade, fez uma referência também ao Teorema de Pitágoras sem perceber.

Novamente os alunos foram questionados da maneira como realizariam esse cálculo de área sem a utilização do aplicativo. "Se fosse um polígono regular seria fácil professor" (aluno, Diário de Bordo, 2018). Outro aluno logo deduziu que poderia decompor a figura em triângulos. Mas a turma percebeu que isso não seria o suficiente, visto que precisariam também saber a medida dos lados e dos ângulos desses triângulos que seriam formados na decomposição, para assim conseguiram encontrar as áreas dos triângulos que, segundo eles, seria possível por meio do Teorema de Pitágoras e das razões trigonométricas.

Foram questionados novamente, mas vocês conseguiriam calcular a área dos triângulos formados na figura usando apenas o Teorema de Pitágoras e as razões trigonométricas? Um aluno respondeu que não, pois provavelmente os triângulos formados não teriam ângulos retos. E como faria então? Ficaram em silêncio. Indagou-se, será que não existiria uma forma de calcular? Talvez com a lei dos Senos e dos Cossenos? Um aluno disse que sim, e logo respondeu que com estas leis seria possível fazer o cálculo procurado, desde que tivessem algumas informações sobre a medida dos lados e ângulos do polígono, como anteriormente já havia sido colocado. Assim, é possível perceber a apropriação dos conceitos matemáticos envolvidos no cálculo da área da poligonal coletada. Nesse sentido, Borba e Penteado (2007, p. 49) afirmam que não acreditam "[...] que a informática irá terminar com a escrita ou com a oralidade, nem que a simulação acabará com a demonstração em matemática. É bem provável que haverá transformações ou reorganizações".

$\mathrm{Na}$ última aula, com o valor das áreas em mãos, foi solicitado aos alunos que calculassem quantas mudas caberiam nas áreas levantadas, uma pelo Geo Area Maps e a outro pelo Topografia App e Google Earth, fazendo assim o cálculo da área média de reflorestamento e levando em conta o espaçamento $2 \mathrm{~m} \times 3 \mathrm{~m}$ entre as mudas, seguindo recomendações técnicas de Ferretti (2002). Também, foi solicitado nesta aula que relatassem sua experiência na atividade.

Ao iniciar o cálculo da quantidade de mudas necessárias para o reflorestar as áreas identificadas, surgiram algumas dúvidas. Um dos alunos foi ao quadro tentar analisar uma maneira de calcular, com a ajuda da turma que disse que poderia dividir a área em espaçamentos $2 \mathrm{~m} \times 2 \mathrm{~m}$ de um lado e $3 \mathrm{~m} \times 3 \mathrm{~m}$ do outro lado, supondo uma área retangular. Assim, todos conseguiram efetuar os 
ISSN: $2446-774 X$

cálculos, porém de maneiras distintas. Um aluno disse que teria uma muda a cada $6 \square^{2}$, explicando seu pensamento: "a primeira muda não posso plantar na divisa, pois é igual ao plantio de café, temos que soltar um espaço, e aí se eu começar a marcar as áreas de $6 \square^{2}$, vou ter uma árvore em cada retângulo". Neste caso referia-se a um retângulo 2x3 (aluno, Diário de Bordo, 2018). Um outro grupo levou em consideração o primeiro espaçamento 2x2 e 3x3 na lateral, deixando assim um espaço $2 \mathrm{~m}$ num lado e $3 \mathrm{~m}$ no outro lado, utilizando como unidade de medida uma área de $180 \square^{2}$ obtendo um total de 1180 mudas, considerando a área média obtida de $10.614 \square^{2}$, conforme Figura 4.

Figura 4 - Cálculo realizado pelos alunos

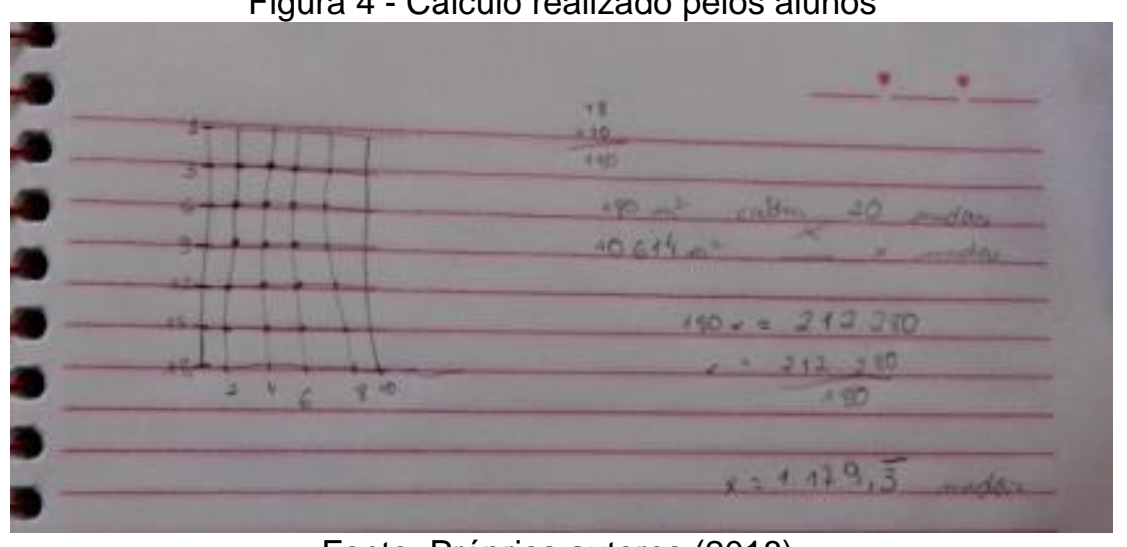

Fonte: Próprios autores (2018).

Notamos que este grupo colocou as mudas na interseção das retas horizontais e verticais que se encontram perpendicularmente, o que na realidade não leva em consideração a quantidade de mudas por uma área retangular 3x2, e sim as mudas plantadas em seus vértices, portanto não foi considerado a última linha na horizontal e nem na vertical, obtendo assim um resultado inferior ao que é necessário na realidade. Nos outros dois cálculos, os grupos deixaram o espaço de $0,5 \mathrm{~m}$ e $1,5 \mathrm{~m}$ na lateral do polígono, o que resultou em uma quantidade maior de mudas na área, no caso 1769 mudas. Estes dois grupos usaram a ideia de uma muda a cada $6 \mathrm{~m}^{2}$. Embora, um dos grupos tenha adotado a unidade padrão de $48 \mathrm{~m}^{2}$, como vemos na figura 5 .

Figura 5 - Cálculo de unidade padrão de $48 \mathrm{~m}^{2}$

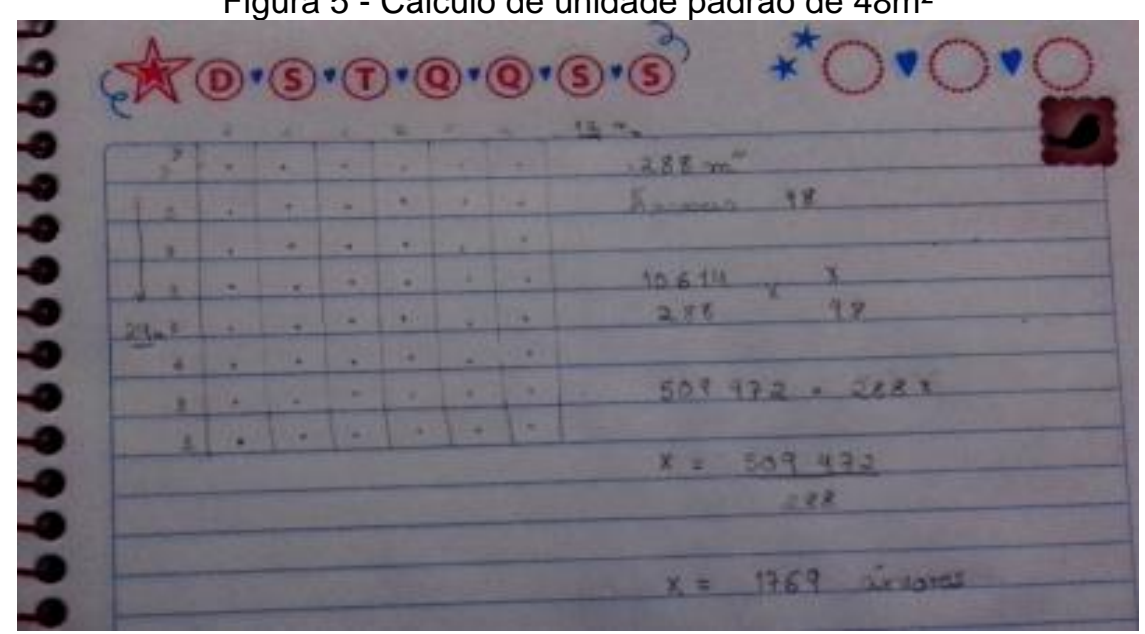

Fonte: Próprios autores (2018). 


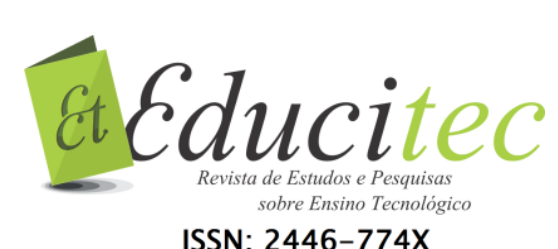

De acordo com Ferretti (2002, p. 38) com relação ao reflorestamento:

\begin{abstract}
O espaçamento de plantio varia em função do solo, relevo, presença de plantas invasoras e disponibilidade de máquinas e implementos agrícolas. Os mais utilizados são: $2,0 \mathrm{~m} \times 2,0 \mathrm{~m}$ (2.500 mudas por hectare); 2,5 m x $2,0 \mathrm{~m}$ (2.000 mudas por hectare) e 3,0 m x 2,0 m (1666 mudas por hectare). Em áreas muito infestadas por plantas invasoras, recomenda-se o uso de duas linhas de espécies de crescimento rápido para cada linha de espécies de crescimento lento.
\end{abstract}

Portanto, para o espaçamento de $2 \times 3$, o cálculo de 1769 mudas, obtido pelos dos dois últimos grupos está correto, levando em consideração a área obtida com auxílio dos aplicativos que foi superior a um hectare, nos caso $10614 \mathrm{~m}^{2}$. Nos três cálculos é possível notar o uso da proporcionalidade para determinar o quantitativo de mudas. Primeiro admitiu-se uma unidade padrão, no caso o quantitativo de mudas por " $\mathrm{x} \mathrm{m}^{2}$ ", para então a partir do raciocínio proporcional descobrir quantas mudas caberiam nas duas áreas identificadas. Ao final tentouse uma parceria (ainda não consolidada) com a Prefeitura Municipal para obtenção das mudas, pois,

\begin{abstract}
Desafios relevantes estariam associados ao custo da recomposição (normalmente superior a $\mathrm{R} \$ 10$ mil por ha) e as demandas técnicas, entre as quais, a disponibilidade regional de sementes e mudas e a oferta de serviços de planejamento, plantio e condução da recomposição das áreas (MACHADO; ANDERSON; 2016, p. 49).
\end{abstract}

\title{
Analisando os relatos finais dos alunos
}

Nesta etapa foi percebido o entusiasmo dos alunos, onde se destacou a grande utilidade das tecnologias no desenvolvimento dos conceitos matemáticos, contribuindo para construção da sustentabilidade do meio rural. Destacamos a percepção de uma aluna, de uma classe social menos favorecida em termos econômicos, evidenciando sua preocupação com o meio ambiente, mas também com sua subsistência. Isto sinaliza para a necessidade da adoção de políticas públicas que minimizem tais vulnerabilidades, no sentido de compensar certas desigualdades sociais, reduzindo os riscos sociais a que estão expostos os menos favorecidos.

Não poderíamos deixar de apresentar uma conclusão de um aluno, que representa a opinião dos demais não citados, na qual destaca-se os benefícios da tecnologia, do uso dos aplicativos no cotidiano, facilitando a vida e as atividades do campo: "foi uma experiência muito boa, pois saímos um pouco da sala de aula, é muito chato ficar só na sala e só na parte teórica dos conteúdos. Os aplicativos são muito úteis e poderiam ser usados também em nossa propriedade para comparar os dados do topógrafo". Portanto é necessário que o professor se aproprie destes conhecimentos, faça uso de tecnologias e leve estes conhecimentos para a sala de aula, tornando-a mais dinâmica, atrativa e contextualizada com o ambiente e realidade social dos alunos.

\section{Conclusão}

Ao buscar aplicativos que auxiliem no cálculo de áreas a serem reflorestadas, 


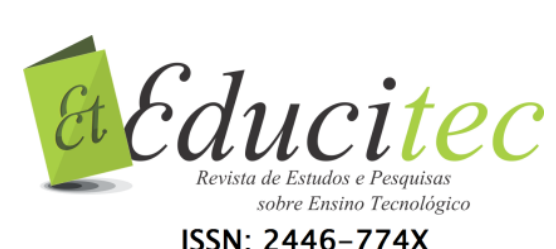

ISSN: 2446-774X

constatamos que muitos softwares foram criados com essa finalidade, no entanto foi preciso selecionar aqueles que além de realizar esses cálculos, fossem de fácil entendimento/manuseio e de uso offline, ou seja, funcionasse sem a necessidade de internet, visto que o tempo foi curto para apresentar os aplicativos aos alunos e estes seriam utilizados em campo onde não teriam acesso a internet. Nesse ínterim, os três aplicativos selecionados e utilizados nesta pesquisa foram de grande relevância para o alcance dos objetivos antes traçados. Por meio dos mesmos e uma efetiva mediação do docente, foi possível motivar os alunos para discussão de conceitos matemáticos, além de mostrar como tecnologias digitais podem ser utilizadas como facilitadoras na resolução de cálculos que os alunos realizam em seu cotidiano.

Percebemos quão rica foi a experiência envolvendo as tecnologias digitais, a matemática e o tema transversal sobre o meio ambiente, pois a construção de relações e conexões entre as diferentes áreas de conhecimento fica nítida. Aqui compactuamos com Borba e Penteado (207, p. 65) que afirmam que "[...] a inserção de Tecnologia da Informação no ambiente escolar tem sido vista como um potencializador das ideias de se quebrar a hegemonia das disciplinas e impulsionar a interdisciplinaridade". Assim, acreditamos que o uso das tecnologias digitais nos permitiu promover uma abordagem rica e diferenciada da matemática, possibilitando acima de tudo uma visão crítica do aluno para com os problemas do seu meio social e ambiental.

Ressaltamos a facilidade que os alunos apresentaram em manusear os aplicativos, e suas participações nas aulas, visto que se tratava de um assunto de interesse e pertinente ao seu contexto social, onde puderam usar as ferramentas tecnológicas, com as quais têm grande intimidade e facilidade no uso, e que muitas vezes são usados apenas com ferramentas de lazer, não sendo, desta maneira, explorados todo o seu potencial educativo. Percebemos, também, que a maioria dos conceitos, seja da matemática, da topografia ou relacionados ao meio ambiente, surgiram de forma natural, entrelaçadas entre si e com a temática do reflorestamento. Possibilitou-se, portanto, uma abordagem que fugiu a exposição maçante de conteúdos, como ocorre tradicionalmente. Assim, a contribuição mais rica que fica é a reflexão acerca da realidade local, no caso, das problemáticas do contexto pesquisado e, principalmente das soluções que podem ser encontradas por meio destas, possíveis pelo diálogo entre as disciplinas escolares com as tecnologias digitais e problemáticas locais, neste caso, o reflorestamento.

\section{Referências}

BRASIL. Parâmetros curriculares nacionais: terceiro e quarto ciclos: apresentação dos temas transversais / Secretaria de Educação Fundamental. Brasília: MEC/SEF, 1998. 436 p.

BRASIL. Lei ํo 12.651, de 25 de maio de 2012. Diário oficial da união. Poder Legislativo, Brasília - DF.

BORBA, M. de C.; PENTEADO, M. G. Informática e Educação matemática. 3. 


\section{Edecitec}

ISSN: $2446-774 X$

Ed.2. reimp. Belo Horizonte: Autêntica, 2007.

CALDAS, W. K.; NOBRE, I. A. M; GAVA, T. B. S. O uso do computador na educação: desafios tecnológicos e pedagógicos. In: NOBRE, I. A. M. [et al] (Org.). Informática na Educação: um caminho de possibilidades e desafios. Serra, ES: Instituto Federal de Educação e Tecnologia do Espírito Santo, 2011.

D AMBROSIO, U. A influência da tecnologia no fazer matemático ao longo da história. Ubiratan D'Ambrósio: é impossível evitar a diversidade de culturas. São Paulo, 22 de fevereiro de 2011. Disponível em: http://professorubiratandambrosio.blogspot.com.br/2011/02/influencia-datecnologia-no-fazer.html. Acesso em: 10 abr 2018.

FÁVERO, R. da P; NUNES, V. B. Os projetos de aprendizagem e às TICs. In: NOBRE, Isaura M. [et al] (Org.). Informática na Educação: um caminho de possibilidades e desafios. Serra, ES: Instituto Federal de Educação e Tecnologia do Espírito Santo, 2011.

FERRETTI, A. R. Modelos de Plantio para a Restauração. In.: GALVÃO, A. P. M.; MEDEIROS, A. C. de S. (Ed.). Restauração da Mata Atlântica em áreas de sua primitiva ocorrência natural. Colombo: Embrapa Florestas, 2002.

MACHADO, F.; ANDERSON, K. Novo código florestal brasileiro: guia para tomadores de decisão em cadeias produtivas e governos - Brasília (DF): WWF Brasil, 2016. 60 p.: il.; $21 \times 29,7 \mathrm{~cm}$.

MORAN, J. M. A integração das tecnologias na educação. 5 ed. Campinas: Papirus, 2013.

NOSELLA, P. Educação no campo: origens da pedagogia da alternância no Brasil. Vitória: EDUFES, 2012.

REIS, J. B. A. O conceito de tecnologia e tecnologia educacional para alunos do ensino médio e superior. In: CONGRESSO DE LEITURA DO BRASIL. 2009. Os anais do 12 COLE. Campinas- SP, 2009.

UNESCO. Diretrizes de Políticas da Unesco para Aprendizagem Móvel. $2014 . \quad$ Disponível em: <http://unesdoc.unesco.org/images/0022/002277/227770por.pdf>. Acesso em: 18 abr. 2018.

VASCONCELOS, C. A.; LIMEIRA, K. M.; SILVA, I. B. da. Do real ao virtual: discutindo concepções de alunos da EAD sobre TIC e ensino-aprendizagem da matemática. $2015 . \quad$ Disponível em: $<$ www.santoangelo.uri.br/anais/ciecitec/2015/resumos/comunicacao/979.doc>. Acesso em: 24 ago. 2018.

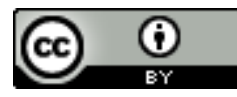

